on-line at: www.actabp.pl

\title{
Interaction of anesthetic supplement thiopental with human serum albumin
}

\author{
Shahper N. Khan ${ }^{1}$, Barira Islam ${ }^{1}$, M. R. Rajeswari², Hammad Usmani ${ }^{3}$, \\ and Asad U. Khan ${ }^{1 凶}$ \\ ${ }^{1}$ Interdisciplinary Biotechnology Unit, Aligarh Muslim University, Aligarh, India; ${ }^{2}$ Department of Biochemistry, \\ All India Institute of Medical Sciences, New Delhi, India; ${ }^{3}$ Department of Anesthesiology, JN Medical College, \\ AMU, Aligarh, India
}

Received: 18 August, 2007; revised: 15 January, 2008; accepted: 31 January, 2008

available on-line: 01 February, 2008

\begin{abstract}
Thiopental (TPL) is a commonly used barbiturate anesthetic. Its binding with human serum albumin (HSA) was studied to explore the anesthetic-induced protein dysfunction. The basic binding interaction was studied by UV-absorption and fluorescence spectroscopy. An increase in the binding affinity $(K)$ and in the number of binding sites $(n)$ with the increasing albumin concentration was observed. The interaction was conformation-dependent and the highest for the $F$ isomer of HSA, which implicates its slow elimination. The mode of binding was characterized using various thermodynamic parameters. Domain II of HSA was found to possess a high affinity binding site for TPL. The effect of micro-metal ions on the binding affinity was also investigated. The molecular distance, $r$, between donor (HSA) and acceptor (TPL) was estimated by fluorescence resonance energy transfer (FRET). Correlation between the stability of the TPL-N and TPL-F complexes and drug distribution is discussed. The structural changes in the protein investigated by circular dichroism (CD) and Fourier transform infrared (FT-IR) spectroscopy reflect perturbation of the albumin molecule and provide an explanation for the heterogeneity of action of this anesthetic.
\end{abstract}

Keywords: thiopental, fluorescence resonance energy transfer, thermodynamics, FT-IR, circular dichroism

\section{INTRODUCTION}

Anesthetic agents have been administered to humans for more than 150 years to provide anesthesia for surgical operations, but their influence on biochemical or physiological processes and the molecular nature of the interactions underlying the functional effect are still poorly understood. Thiopental (TPL), an intravenous barbiturate anesthetic (Fig. 1), is used frequently by anesthesiologists prior to surgery and other invasive medical procedures. In addition to its pharmacological action spectra, TPL is known to exhibit varied effects, e.g. it increases pulmonary inflammation (Giraud et al., 1998), affects bilegenic functions of liver (Skarlosh, 1974), causes drowsiness in the newborn baby as the drug passes into breast milk; its increased toxicity with higher dose administration has also been reviewed (Krier et al., 1984; Schalen et al., 1992). Human serum albumin (HSA, $66.5 \mathrm{kDa}$ ) is the most abundant protein in the blood serum with a concentration of about $0.63 \mathrm{mM}$. It is a single polypeptide chain of 585 amino acids (Dugiaczyk et al., 1982) with a largely helical ( $\approx 57 \%$ ) triple-domain structure that assembles to form a heart-shaped molecule. Other mammalian albumins are highly homologous with human albumin, all of which contain 17 disulfide bridges. HSA considerably contributes to colloid osmotic blood pressure and participates in the transport and distribution of many molecules and metabolites (Peters, 1996). It

Corresponding author: Asad U. Khan, Interdisciplinary Biotechnology Unit, Aligarh Muslim University, Aligarh 202002, India; phone: 0091-571-2723088; fax: 0091-571-2721776; e-mail: huzzi99@hotmail.com

Abbrevaiations: ATR, attenuated total reflection; CD, circular dichroism; ext. excitation; FRET, fluorescence resonance energy transfer; FT-IR, Fourier transform infrared spectroscopy; HSA, human serum albumin; MRE, mean residual ellipticity; TPL, thiopental. 


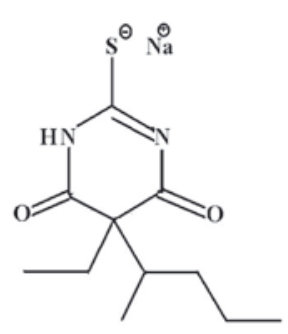

Figure 1. Chemical structure of thiopental, a barbiturate anesthetic.

has been shown that the distribution, free concentration and the metabolism of various drugs can be significantly altered as a result of their binding to HSA (Kragh-Hansen, 1981). In studying the interaction of drugs and proteins, fluorescence techniques are commonly used because of their high sensitivity, rapidity and ease of implementation. FT-IR, a powerful technique for the study of hydrogen bonding, has recently become very popular for structural characterization of proteins. For secondary-structure analysis of protein, circular dichroism (CD) spectroscopy is a technique used most frequently. Several reports have been published studying the interaction of proteins with drugs by fluorescence technique (Tian et al., 2003; Sereikaite et al., 2006; Khan et al., 2007), FT-IR (Neault et al., 1998) and CD spectroscopy (Chamouard et al., 1985) but no such data characterizing the mechanism of binding HSA with TPL and the accompanied structural alteration is available. The above methods have advantages over conventional approaches such as affinity and size exclusion chromatography, equilibrium dialysis, ultrafiltration and ultracentrifugation, which suffer from a lack of sensitivity, long analysis time, or both, and use protein concentrations far in excess of the dissociation constant for the drug-protein complex (Epps et al., 1999).

\section{EXPERIMENTAL}

\section{Materials}

Human serum albumin (HSA) of 99\% purity was obtained from Sigma Chemical Company (St. Louis, USA). Thiopental (sodium thiopentone) was purchased from Ranbaxy (India). The solutions of TPL and HSA were prepared in $10 \mathrm{mM}$ phosphate buffer of $\mathrm{pH}$ 7.4. HSA solutions were prepared based on its relative molecular mass of 66500 . Salts of different metals, phosphate, acetate, glycine and urea were purchased from Merck (India). The protein concentration was determined spectrophotometrically using the absorption coefficient of 36500 $\mathrm{M}^{-1} \mathrm{~cm}^{-1}$ at $280 \mathrm{~nm}$ (Painter et al., 1998). All other materials were of analytical reagent grade and double distilled water was used throughout.
Apparatus

The absorbance spectra were recorded on a double beam Shimadzu UV-Vis spectrophotometer UV-1700 using a cuvette of $1 \mathrm{~cm}$ path length. Fluorescence measurements were performed on a spectrofluorimeter Model RF-5301PC (Shimadzu, Japan) equipped with a $150 \mathrm{~W}$ Xenon lamp and a slit width of $10 \mathrm{~nm}$. A $1.00 \mathrm{~cm}$ quartz cell was used for measurements. The $\mathrm{CD}$ measurements were made on a JASCO-J-820 spectropolarimeter (Tokyo, Japan) using a $0.1 \mathrm{~cm}$ cell at $0.2 \mathrm{~nm}$ intervals, with three scans averaged for each $C D$ spectrum in the range of 200-350 nm. FT-IR measurements were made at room temperature on a Nicolet Nexus 670 FT-IR spectrometer (USA) equipped with a germanium attenuated total reflection (ATR) accessory, a DTGS $\mathrm{KBr}$ detector and a $\mathrm{KBr}$ beam splitter.

\section{Procedures}

UV measurements. The UV measurements of HSA in the presence and absence of TPL were made in the range of 200-300 $\mathrm{nm}$ and HSA concentration was fixed at $12 \mu \mathrm{M}$ while the drug concentration was varied from 12 to $48 \mu \mathrm{M}$.

Drug-protein interactions. The HSA concentration was fixed at $3 \mu \mathrm{M}$ unless mentioned otherwise and the drug concentration was varied from 3 to $30 \mu \mathrm{M}$. Fluorescence spectra were recorded at three temperatures $(298,308$ and $318 \mathrm{~K})$ in the range of $300-400 \mathrm{~nm}$ upon excitation at $280 \mathrm{~nm}$. To evaluate the effect of ionic environment on interaction the ionic strength was maintained with $\mathrm{NaCl}$ at 100, 200 or $400 \mathrm{mM}$. In substrate-dependent binding the three protein concentrations taken were 3, 6 and $9 \mu \mathrm{M}$.

Conformation-dependent interaction. $\mathrm{Hu}-$ man serum albumin exits in different conformational states as the N, B, F and I forms (Ahmad et al., 2006). The $\mathrm{N}, \mathrm{B}, \mathrm{F}$ and I conformations were prepared by mixing $20 \mu \mathrm{l}$ of HSA monomer stock solution $(250 \mu \mathrm{M})$ with $980 \mu \mathrm{l}$ of $\mathrm{pH} 7(60 \mathrm{mM}$ phosphate), pH 9 (10 mM glycine/ $\mathrm{NaOH}), \mathrm{pH} 3.5$ (10 mM acetate) buffers and $10 \mathrm{M}$ urea was added as per the required concentration. The existence of different isomers in the experimental preparations was confirmed basing on the various fluorescence properties of the different forms. The $\lambda_{\max }$ of the $\mathrm{N}$ form $=344$ (ext. $295 \mathrm{~nm}$ ), 339.3 (ext. $280 \mathrm{~nm}$ ); $\lambda_{\max }$ of the B form $=340($ ext. $295 \mathrm{~nm}), 334$ (ext. $280 \mathrm{~nm}) ; \lambda_{\max }$ of the $\mathrm{F}$ form $=344$ (ext. $295 \mathrm{~nm}), 334.6$ (ext. $280 \mathrm{~nm}) ; \lambda_{\max }$ of the I form = 344 (ext. $295 \mathrm{~nm}$ ), 341 (ext. $280 \mathrm{~nm}$ ) and fluorescence intensity of N, B, F and I forms are 101, 96, 115 and 71, respectively, with excitation and emission slits at 5 and $10 \mathrm{~nm}$.

Fourier transform infrared (FT-IR) spectroscopy. All spectra were taken via the attenuated total 
reflection (ATR) method with resolution of $4 \mathrm{~cm}^{-1}$ and 60 scans. Spectra processing procedure: spectra of buffer and protein solution were collected at the same conditions. Then, buffer spectrum is subtracted from the spectra of sample solution to get the FTIR spectra of proteins. The subtraction criterion was that the original spectrum of protein solution between 2200 and $1800 \mathrm{~cm}^{-1}$ was without any important feature (featureless) (Surewicz et al., 1993).

Circular dichroism (CD) measurements. The $\mathrm{CD}$ measurements of HSA in the presence and absence of TPL were made in the range of 200-300 nm using a $0.1 \mathrm{~cm}$ cell at $0.2 \mathrm{~nm}$ intervals with three scans averaged for each CD spectrum. A $150 \mu \mathrm{M}$ stock solution of each form of HSA was prepared in $10 \mathrm{mM}$ phosphate buffer. The molar ratios of HSA to drug concentration were 1:10, 1:11, 1:12 and 1:14.

Energy transfer between TPL and protein. The absorbance spectrum of TPL $(3 \mu \mathrm{M})$ was recorded in the range of $300-400 \mathrm{~nm}$. The emission spectrum of HSA $(3 \mu \mathrm{M})$ was also recorded in the range of 300-400 nm. The overlap of the UV absorbance spectrum of TPL with the fluorescence emission spectrum of the protein was used to calculate the energy transfer.

Effects of some divalent ions. Fluorescence spectra of TPL-HSA were recorded in the presence and absence of various ions, viz., $\mathrm{Cu}^{2+}, \mathrm{Fe}^{3+}, \mathrm{Ni}^{2+}$, $\mathrm{Zn}^{2+}, \mathrm{Mn}^{2+}$ and $\mathrm{Ca}^{2+}$ and in the range of $300-400$ $\mathrm{nm}$ upon excitation at $280 \mathrm{~nm}$. The concentration of HSA was fixed at $3 \mu \mathrm{M}$ and that of the common ion was maintained at $10 \mu \mathrm{M}$.

\section{RESULTS AND DISCUSSION}

\section{UV-Vis absorbance studies}

The interaction between TPL-HSA was studied from the UV-Vis absorbance spectral data (Fig. 2). The UV absorbance intensity of HSA increased with the increasing TPL concentration. The addition of the drug results in a distinct shift of the TPL-HSA spectrum toward longer wavelength (red shift). These results clearly indicated an interaction and some complex formation between TPL and HSA (Hu et al., 2004; Cui et al., 2004).

\section{Binding of TPL to HSA}

Fluorescence measurements can give some information on the binding of small molecules to the protein, such as the binding mechanism, binding mode, binding constants, binding sites and intermolecular distances. Fluorescence intensity of a compound can be decreased by a variety of molecular interactions, viz., excited-state reactions, molecular

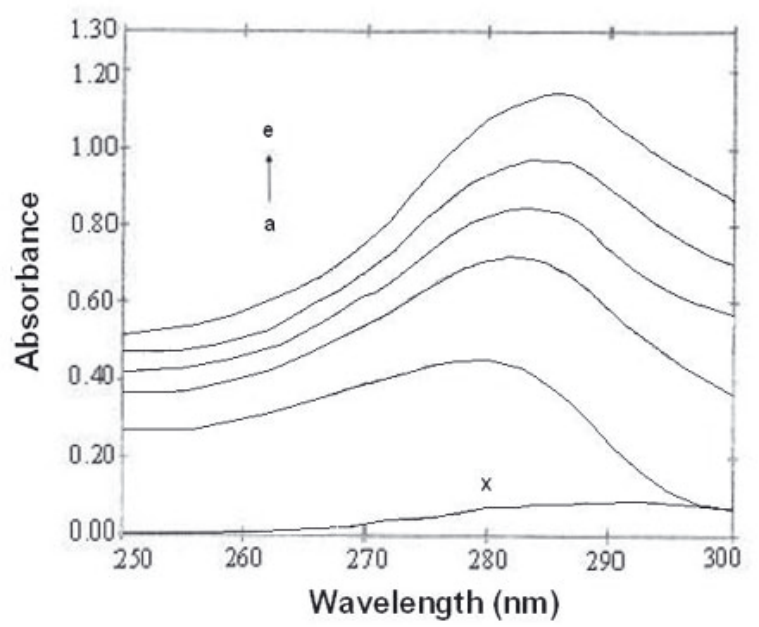

Figure 2. Absorbance spectra of HSA, TPL and HSA-TPL system.

HSA concentration was $12 \mu \mathrm{M}$ (a). TPL concentration for TPL-HSA system was at $12 \mu \mathrm{M}$ (b), $24 \mu \mathrm{M}$ (c), $36 \mu \mathrm{M}$ (d) and $48 \mu \mathrm{M}(\mathrm{e})$. A concentration of $12 \mathrm{mM}$ TPL (x) was used for TPL only.

rearrangements, energy transfer, ground state complex formation and collisional quenching. Such a decrease in intensity is called quenching. Fluorescence spectra of HSA in the presence of different amounts of TPL were recorded in the range of $300-400 \mathrm{~nm}$ upon excitation at $280 \mathrm{~nm}$. TPL caused a concentration-dependent quenching of the intrinsic fluorescence of HSA (Fig. 3) without changing the emission maximum and shape of the peaks. These results indicated that there were interactions between TPL and HSA and the binding resulted in a non-fluorescent complex. The fluorescence quenching data was analyzed by the Stern-Volmer equation:

$F_{0} / F=1+K_{\mathrm{SV}}[\mathrm{Q}]$

where $F_{0}$ and $F$ are the steady-state fluorescence intensities in the absence and presence of quencher, respectively, $K_{\mathrm{SV}}$ the Stern-Volmer quenching constant and [Q] is the concentration of quencher (TPL). The values of $K_{\mathrm{SV}}$ and $\mathrm{R}^{2}$ (regression coefficient) are shown in Table 1 . The pattern of the $F_{0} / F$ versus [Q] (Stern-Volmer) plots for HSA (Fig. 4) revealed the quenching type, may be static or dynamic, since the characteristic Stern-Volmer plot of combined quenching (both static and dynamic) is an upward curve (as in the Fig. 4). Stern-Volmer plot, however, does not define per se the quenching type in the present study, and an additional information is required for this determination. One way to distinguish dynamic from static quenching is to examine the temperature effect on the interaction of the drug with HSA. The $K_{\mathrm{SV}}$ values decrease with an increase in temperature for static quenching, but the reverse 


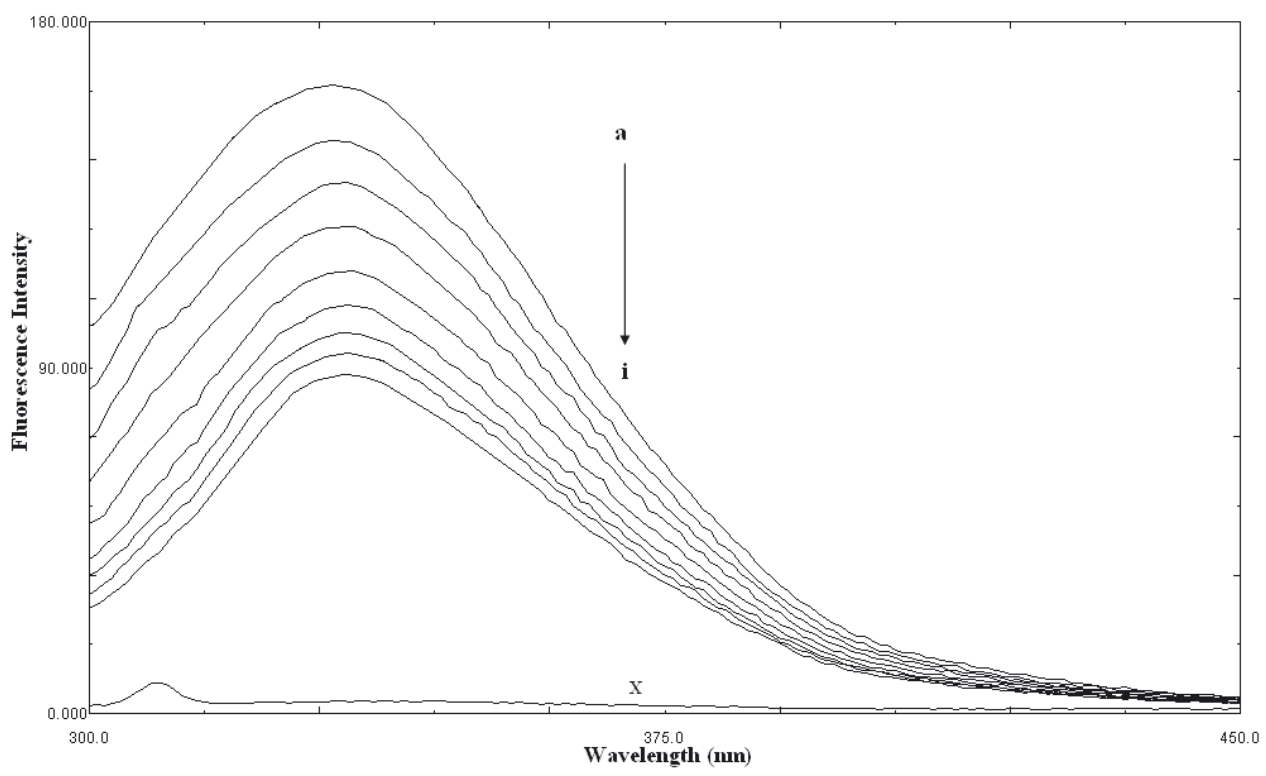

Figure 3. Fluorescence emission spectra of HSA in the absence and presence of TPL.

HSA at $3 \mu \mathrm{M}$ (a) in phosphate buffer, $\mathrm{pH} 7.4$, temperature $298 \mathrm{~K}$ in the absence and presence of TPL after excitation at $280 \mathrm{~nm}$. The TPL concentration was $3 \mu \mathrm{M}$ (b), $6 \mu \mathrm{M}$ (c), $9 \mu \mathrm{M}$ (d), $12 \mu \mathrm{M}$ (e), $15 \mu \mathrm{M}(\mathrm{f}), 18 \mu \mathrm{M}(\mathrm{g}), 21 \mu \mathrm{M}(\mathrm{h}), 24 \mu \mathrm{M}$ (i) and $3 \mu \mathrm{M}$ TPL alone (x).

effect will be observed for dynamic quenching. The results of the present study indicate that the probable quenching mechanism of fluorescence of HSA by TPL is static quenching. The mechanism of quenching was further confirmed from the values of quenching rate constants, $\mathrm{Kq}$, which are evaluated using the equation:

$K \mathrm{q}=K_{\mathrm{SV}} / \tau_{0}$

where $\tau_{0}$ is the average lifetime of the protein without the quencher. Various values of fluorescence lifetime for HSA have been reported but the average fluorescence lifetime used was about 5 ns (Gelamo et al., 2002) and hence the values of $\mathrm{Kq}$ were of the order of $10^{11} \mathrm{~L} \cdot \mathrm{mol}^{-1} \cdot \mathrm{s}^{-1}$ (Table 1), which is greater then the

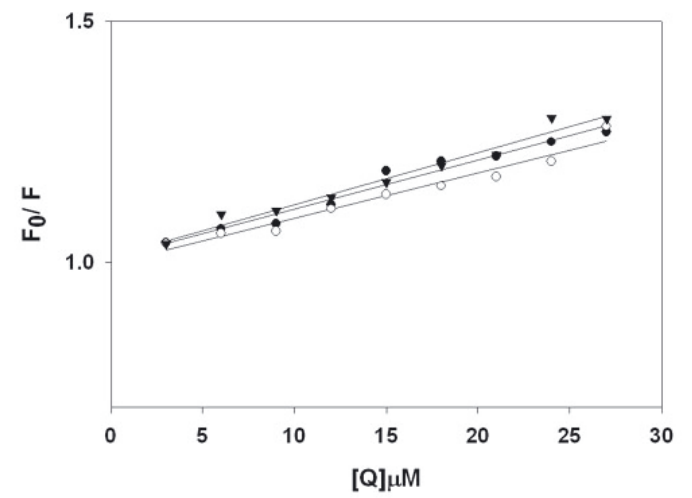

Figure 4. Stern-Volmer plot for the binding of TPL with HSA.

Data for: $298 \mathrm{~K}(\bullet), 308 \mathrm{~K}(\mathrm{O})$ and $318 \mathrm{~K}(\boldsymbol{\nabla})$ are shown. maximum scatter collision quenching constant $\mathrm{Kq}(2$ $\times 10^{10} \mathrm{~L} \cdot \mathrm{mol}^{-1} \cdot \mathrm{s}^{-1}$ ) for various quenchers with a biopolymer. This implies that the quenching is initiated by the formation of a complex (Ware, 1962).

\section{Analysis of binding equilibria}

When small molecules bind independently to a set of equivalent sites on a macromolecule, the equilibrium between free and bound molecules is given by the equation (Feng et al., 1998; Gao et al., 2004):

$\log \left[\left(F_{0}-F\right) / F\right]=\log K+n \log [Q]$

where $K$ and $n$ are the binding constant and the number of binding sites, respectively. Thus, the plot of $\log \left(F_{0}-F\right) / F$ versus $\log [Q]$ can be used to determine $K$ as well as $n$. The values of $K$ were found to be $(2.52 \pm 0.021) \times 10^{3}, \quad(2.20 \pm 0.042) \times 10^{3}$ and $(1.74 \pm 0.056) \times 10^{3} \mathrm{M}^{-1}$ for HSA at 298,308 and $318 \mathrm{~K}$, respectively. The values of $n$ were $(0.86 \pm 0.02),(0.86 \pm 0.06)$ and $(0.82 \pm 0.04)$, respectively, at 298,308 and $318 \mathrm{~K}$. It was found that the binding constant decreased with an increase in temperature, resulting in the destabilization of the TPL-HSA complex. Meanwhile, from the data of $n$ it may be inferred that there is one independent class of binding sites on HSA for TPL.

\section{Substrate-dependent binding}

It was observed that the binding increased with the increasing concentration of albumin (sub- 
Table 1. Thermodynamic parameters of HSA-TPL system

\begin{tabular}{|c|c|c|c|c|c|c|}
\hline $\mathrm{T}(\mathrm{K})$ & $K_{\mathrm{SV}} \times 10^{3}\left(\mathrm{~L} \mathrm{~mol}^{-1}\right)$ & $\mathrm{Kq} \times 10^{11}\left(\mathrm{~L} \mathrm{~mol}^{-1} \mathrm{~s}^{-1}\right)$ & $R^{2}$ & $\Delta G^{\circ}\left(\mathrm{KJ} \mathrm{mol}^{-1}\right)$ & $\Delta H^{\circ}\left(\mathrm{KJ} \mathrm{mol}^{-1}\right)$ & $\Delta S^{\circ}\left(\mathrm{J} \mathrm{mol}^{-1} \mathrm{~K}^{-1}\right)$ \\
\hline 298 & $1.00 \pm 0.04$ & $2.000 \pm 0.041$ & 0.9675 & $-19.421 \pm 0.007$ & & \\
\hline 308 & $0.98 \pm 0.05$ & $1.960 \pm 0.050$ & 0.9580 & $-19.723 \pm 0.004$ & $-14.06 \pm 0.04$ & $18.02 \pm 0.03$ \\
\hline 318 & $0.95 \pm 0.02$ & $1.900 \pm 0.022$ & 0.9708 & $-19.730 \pm 0.006$ & & \\
\hline
\end{tabular}

strate) at fixed TPL (ligand) molar ratios. The quenching effect increases with the higher concentration of albumin (Fig. 5), resulting in an increase in the magnitude of binding affinity and binding capacity of this interaction (Table 2). This confirms the strengthening of binding forces governing the reaction. This could be explained by the fact that each albumin molecule represents a large lipophilic or at least hydrophobic area for the lipophilic TPL, which provides a better site for localization of TPL molecules.

Our study suggests that even a single dose of the drug can cause pronounced alteration in physico-chemical properties of bound protein.

\section{Conformation-dependent binding}

The transition of serum albumin from $\mathrm{N}$ to $\mathrm{B}$ and $\mathrm{B}$ to $\mathrm{F}$ led to a change in its conformational state. Figure 6 shows pronounced quenching in the F-form compared to other two forms. This difference in fluorescence quenching/TPL binding pattern here could be attributed to a change in protein conformation. This may be due to a close exposure of the drug to its binding site due to unfolding and breakage of interdomain bridges in the protein. Conformation-dependent reduction in binding parameters has also been described previously for warfarin (Wilting et al., 1980).

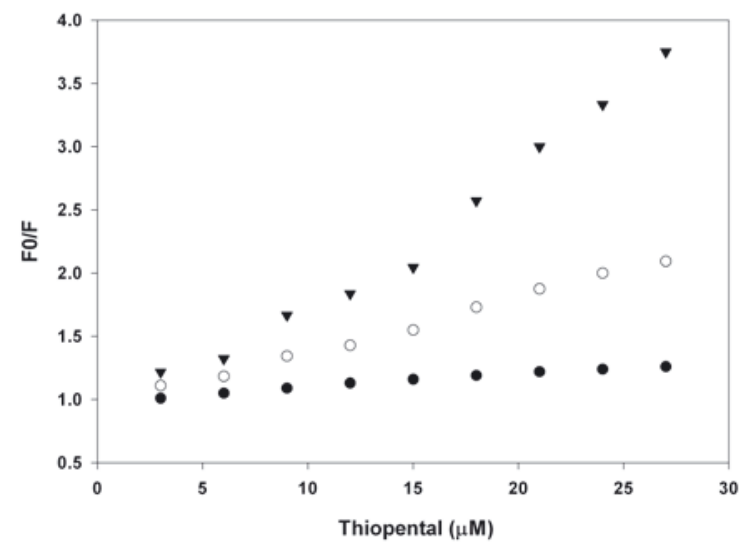

Figure 5. Stern-Volmer plot for the binding of TPL with HSA at different concentrations.

Concentration of HSA were $(\bullet) 3 \mu \mathrm{M},(\mathrm{O}) 6 \mu \mathrm{M},(\boldsymbol{\nabla})$ $9 \mu \mathrm{M}$. This shows the magnification of drug interaction of same dose in the presence of higher concentration of albumin.

\section{Correlation of conformation with drug distribution}

Binding in the serum can influence drug distribution in the body and the magnitude of the effect will depend on the strength of $K_{a}$ and on the dose of the drug (Ryan et al., 2004). The stability of the complex in acidic conditions is of immense physiological relevance in view of its elimination and excretion. The complex of TPL with the F-conformation of HSA is much stronger than those with the other, $\mathrm{N}$ and $\mathrm{B}$, forms as indicated by the association constants (Table 3). The increase in the binding affinities with conformational transition of HSA may strongly affect both the dose-response relationship and the rate of drug elimination (Borga \& Borga, 1997 Ryan et al., 2004). The dose response relationship and the rate of drug elimination depend on the fraction of free drug $\left(\alpha_{\mathrm{f}}\right)$ in the body, and the fraction of total drug present in the free form $\left[\mathrm{D}_{\mathrm{f}}\right]$ depends on $K(1 /$ $K_{\text {dis }}$ ) for a given drug concentration according to the following equation (Martin et al., 1965).

$\alpha_{\mathrm{f}}=\left(K_{\mathrm{dis}}+\left[\mathrm{D}_{\mathrm{f}}\right]\right) /\left(\left[\mathrm{P}_{\mathrm{t}}\right]+K_{\mathrm{dis}}+\left[\mathrm{D}_{\mathrm{f}}\right]\right)$

Where $\left[\mathrm{P}_{\mathrm{t}}\right]$ is total protein concentration and $K_{\text {dis }}$ is dissociation constant. A strongly bound drug at low concentration is concentrated mainly in the blood plasma component. There is a dose range within which a small increase in the dose results in a relatively large increase in the amount of unbound drug. When $\left[\mathrm{D}_{\mathrm{f}}\right] \rightarrow 0, \alpha$ becomes proportional to $K_{\text {dis }}$

$\alpha_{\mathrm{f}}=K_{\mathrm{dis}} /\left(\left[\mathrm{P}_{\mathrm{t}}\right]+K_{\mathrm{dis}}\right)$

At the plasma concentration of HSA $(6.7 \times$ $\left.10^{-4} \mathrm{M}\right)$, the fraction of free TPL was calculated according to Eqn. 5 and was found to be about $71 \%$ higher for the $\mathrm{N}$ isomer as compared to the $\mathrm{F}$ isomer.

\section{$\mathrm{pH}$ dependence of $K$ ascribed to conformational changes of HSA}

Whether the $\mathrm{pH}$ dependence of the binding affinity $K$ resides in the ionic state of TPL or the protein molecule remains an interesting point. The extent of ionization of TPL (Fig. 1) (NH, pK= 8.63) was determined according to Henderson-Hasselbalch:

$\mathrm{pH}=\mathrm{p} K+\log [\alpha /(1-\alpha)]$ 
Table 2. Substrate dependent increase in the binding parameters at constant thiopental concentration

\begin{tabular}{llll}
\hline HSA $[\mu \mathrm{M}]$ & $K\left(\mathrm{M}^{-1}\right)$ & $n$ & $\Delta \mathrm{G}_{\text {binding }}^{\circ}\left(\mathrm{KJ} \mathrm{mol}^{-1}\right)$ \\
\hline 3 & $2.5 \times 10^{3} \pm 0.26$ & $0.86 \pm 0.03$ & $-19.421 \pm 0.007$ \\
6 & $1.8 \times 10^{5} \pm 0.19$ & $1.09 \pm 0.06$ & $-30.241 \pm 0.004$ \\
9 & $8.5 \times 10^{6} \pm 0.08$ & $1.36 \pm 0.02$ & $-39.861 \pm 0.008$ \\
\hline
\end{tabular}

almost the same number of binding capacity in the $\mathrm{F}$ form indicates a better availability of the binding site due to unfolding of domain III. The small decrease in the $(n)$ value may be due to a loss of inter domain interactions which stabilizes the protein domain structure.

where $\alpha$ is the extent of protonation and $\mathrm{pK}$ is the extent of ionization. Using this equation, the following equations were derived which describe the extent of ionization of ionizing groups of TPL at $\mathrm{pH}$ 3.5, 7 and 9.

pH $3.5 \mathrm{pH}=\mathrm{pK}-5.13$ approx. $100 \%-\mathrm{NH}_{2}{ }^{+}$ pH $7.0 \mathrm{pH}=\mathrm{pK}-1.63$ approx. $99 \%-\mathrm{NH}_{2}^{+}$ pH $9.0 \mathrm{pH}=\mathrm{pK}+0.37$ approx. $30 \%-\mathrm{NH}_{2}^{+}$

Based on these, the ionic state of TPL at different $\mathrm{pH}$ values was determined, and it can be noted that TPL has an almost equal positive charge at $\mathrm{pH} 3.5$ and 7.0. The increase in the magnitude of $K$ at acidic $\mathrm{pH}$ and not at neutral $\mathrm{pH}$ indicated that the origin of the $\mathrm{pH}$ dependence of $K$ resided mainly in the protein molecule. This could be clearly explained with the help of the conformational differences at these $\mathrm{pH}$.

\section{Binding site of TPL on domain II}

The acid- and urea-induced unfolding pathway was employed to locate the binding site (Ahmad et al., 2006) for TPL on HSA. HSA undergoes the $\mathrm{N} \rightarrow \mathrm{F}$ and $\mathrm{N} \rightarrow \mathrm{I}$ transitions induced by the acidic $\mathrm{pH}$ between 7.0-3.5 and the urea concentration in the range of 4.8-5.2 M, respectively (Chmelik \& Kalous, 1982; Khan, 1986). The $\mathrm{F}$ isomer, which predominates at $\mathrm{pH} 3.5$, is characterized by unfolding and separation of domain III, and isomer I is characterized by unfolding of domain III and partial but significant loss of native conformation of domain I. Domain II is known to be unaffected by either $\mathrm{N} \rightarrow$ $\mathrm{F}$ or $\mathrm{N} \rightarrow \mathrm{I}$ transitions. Hence, no effect in the number of binding sites (approx. 0.81) of these conformational states compared to native (Table 3 ) is suggestive of the location of the binding sites for TPL on domain II. The increase in the binding affinity and

Table 3. Comparative assessment of quenching constants and TPL binding parameters to isomeric forms of HSA

\begin{tabular}{llll}
\hline HSA isomers & $K\left(\times 10^{3} \mathrm{M}^{-1}\right)$ & $n$ & $\Delta \mathrm{G}_{\text {binding }}^{\circ}\left(\mathrm{KJ} \mathrm{mol}^{-1}\right)$ \\
\hline Native (N) & $2.50 \pm 0.26$ & $0.86 \pm 0.03$ & $-19.421 \pm 0.007$ \\
Basic (B) & $2.48 \pm 0.11$ & $0.90 \pm 0.01$ & $-19.307 \pm 0.002$ \\
Fast moving (F) & $5.42 \pm 0.03$ & $0.82 \pm 0.06$ & $-21.371 \pm 0.003$ \\
Urea induced (I) & $5.29 \pm 0.04$ & $0.80 \pm 0.02$ & $-21.211 \pm 0.006$ \\
\hline
\end{tabular}

\section{Types of interaction force between HSA and TPL}

Considering the dependence of the binding constant on temperature, a thermodynamic process was considered to be responsible for this interaction. Therefore, the thermodynamic parameters dependent on temperature were analyzed in order to further characterize the forces acting between TPL and HSA. The forces acting between a small molecule and a macromolecule mainly include hydrogen bonds, van der Waals forces, electrostatic forces and hydrophobic interaction forces. The thermodynamic parameters, enthalpy change $\left(\Delta H^{\circ}\right)$, entropy change $\left(\Delta S^{\circ}\right)$ and free energy change $\left(\Delta G^{\circ}\right)$ are the main evidence to determine the binding mode. The thermodynamic parameters were evaluated using the following equations:

$\log K=-\frac{\Delta H^{\circ}}{2.303 R T}+\frac{\Delta S^{\circ}}{2.303 R}$

$\Delta G^{\circ}=\Delta H^{\circ}-T \Delta S^{\circ}$

where $K$ and $R$ are the binding constant and gas constant, respectively. The results obtained are shown in Table 1 . The positive entropy change occurs because the water molecules that are arranged in an orderly fashion around the ligand and protein acquire a more random configuration as a result of hydrophobic interactions. A negative $\Delta H^{\circ}$ value is observed whenever there is hydrogen bonding in the binding (Ross \& Subramanian, 1981; Rahman et al., 1993). The negative $\Delta H^{\circ}$ and positive $\Delta S^{\circ}$ values in the case of TPL, therefore, show that both hydrogen bonds and hydrophobic interactions play a role in the binding of TPL to HSA (Aki \& Yamamoto, 1989; Seedher et al., 1999). This is in agreement with the insignificant effect due of functional group ionization on binding (charged species).

\section{Structure-ascribed synchronous fluorescence}

Intrinsic fluorescence of HSA was studied to evaluate tertiary structure changes induced as a result of the interaction between TPL and HSA. Synchronous mode of fluorescence spectroscopy in- 


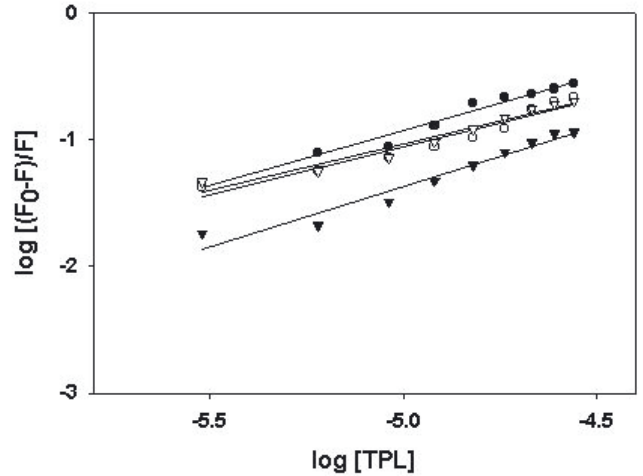

Figure 6. Conformation dependent binding. The plot of $\log \left[\left(F_{0}-F\right) / F\right]$ versus $\log [Q]$ for $(\bullet) \mathrm{N},(\bigcirc) \mathrm{B}$, $(\boldsymbol{\nabla}) \mathrm{F}$ and $(\nabla)$ I conformation of HSA for binding constant and binding sites.

troduced by Llody (1971), was applied to infer the conformational changes of the protein due to this binding reaction. Simultaneous scanning of excitation and the emission wavelengths with a fixed wavelength difference between them was done. It gives information about the change in the molecular environment of the protein due to ligand binding. It provides several advantages over other modes like spectral simplification, reduction in spectral noise and spectral area. According to Miller (1979), the characteristic information of tryptophan residue is obtained when $\Delta \lambda$ difference is maintained at 60 $\mathrm{nm}$. Figure 7 shows that addition of TPL results in strong fluorescence diminution of tryptophan with

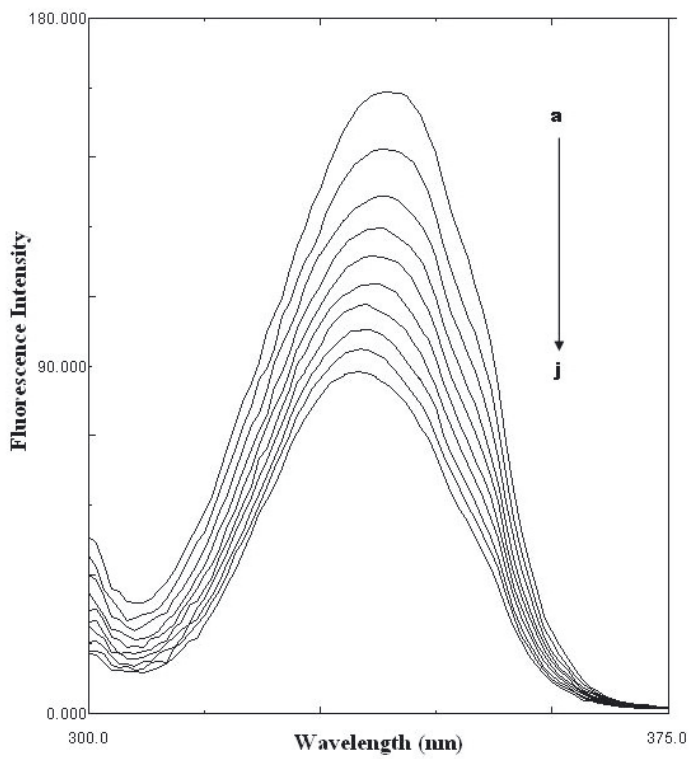

Figure 7. Synchronous fluorescence spectra of HSA.

The spectra of HSA $(3 \mu \mathrm{M})$ with $\Delta \lambda=60 \mathrm{~nm}$ in increasing concentration of TPL: $0 \mu \mathrm{M}$ (a), $3 \mu \mathrm{M}$ (b), $6 \mu \mathrm{M}$ (c), $9 \mu \mathrm{M}$ (d), $12 \mu \mathrm{M}$ (e), $15 \mu \mathrm{M}$ (f), $18 \mu \mathrm{M}$ (g), $21 \mu \mathrm{M}$ (h), $24 \mu \mathrm{M}$ (i) and $27 \mu \mathrm{M}(\mathrm{j})$. the maximum emission wavelength at 338-332 $\mathrm{nm}$. As suggested earlier, the maximum emission wavelength $\left(\lambda_{\max }\right)$ at 330-332 indicated that tryptophan residues are located in a nonpolar region, i.e. they are buried in a hydrophobic pocket in HAS, and $\lambda_{\max }$ at $350-352 \mathrm{~nm}$ shows that tryptophan residues are exposed to water, that is, the hydrophobic cavity in HSA is exposed due to disagglomeration of HSA domains. Figure 7 suggests that TPL mainly bound to the hydrophobic regions of HSA, which is in accordance with the results from the binding mode.

\section{FT-IR measurements}

Additional evidence regarding the TPL-HSA complexations comes from FT-IR spectroscopy results obtained for drug-protein complexes. Infrared spectra of proteins exhibit a number of so-called amide bands which represent different vibrations of the peptide moiety. Of all the amide modes of the peptide group, the single most widely used one in studies of protein secondary structure is amide I. This vibration mode originates from the $\mathrm{C}=\mathrm{O}$ stretching vibration of the amide group (coupled to the inphase bending of the $\mathrm{N}-\mathrm{H}$ bond and the stretching of the $\mathrm{C}-\mathrm{N}$ bond) and gives rise to infrared bands in the region between approx. 1600 and $1700 \mathrm{~cm}^{-1}$
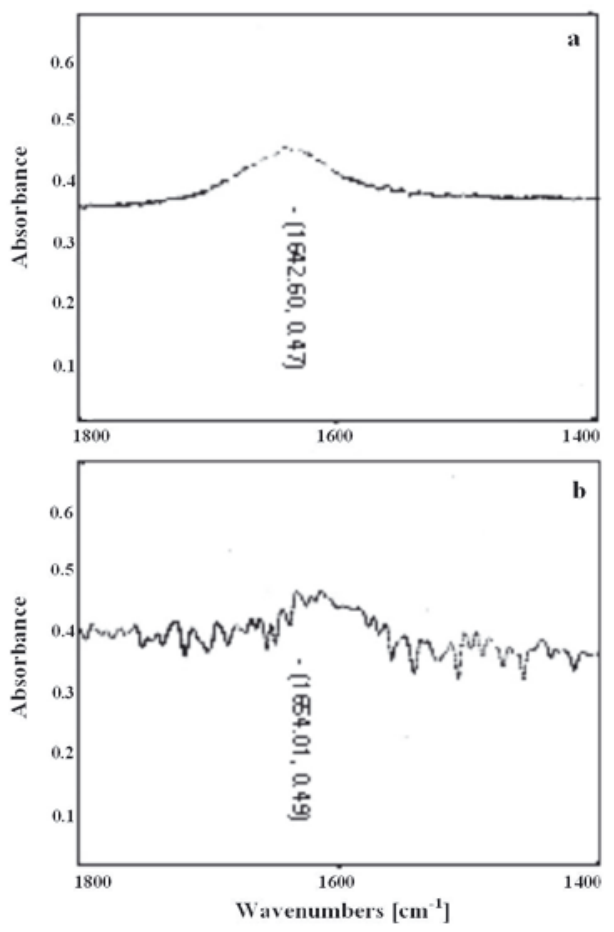

Figure 8. Fourier transform infrared spectroscopy.

FT-IR spectra and difference spectra of HSA in aqueous solution (a) FT-IR spectrum of HSA; (b) FT-IR difference spectrum of HSA obtained by subtracting the spectrum of the TPL+ buffer from that of the TPL-bound form in the region of $1800-1400 \mathrm{~cm}^{-1}$ at physiological $\mathrm{pH}$ (HSA, 3.0 $\mu \mathrm{M}$; TPL, $6.0 \mu \mathrm{M})$. 
Table 4. Alterations in protein secondary structures induced by TPL binding with HSA

\begin{tabular}{|c|c|c|c|c|}
\hline \multicolumn{5}{|c|}{ Structure change $(\%)$} \\
\hline $\begin{array}{l}\text { TPL/HSA } \\
\text { (molar ratio) }\end{array}$ & $\alpha$ & $\beta$ & Turns & Random \\
\hline 0 & 54.6 & 23.2 & 16.2 & 6.0 \\
\hline 10 & 49.6 & 18.5 & 22.5 & 9.4 \\
\hline 11 & 48.2 & 17.4 & 23.1 & 11.3 \\
\hline 12 & 47.4 & 16.6 & 23.8 & 12.2 \\
\hline 14 & 45.8 & 15.7 & 24.6 & 13.9 \\
\hline
\end{tabular}

(Surewicz et al., 1993). The protein amide bands have a relationship with the secondary structure of protein, and amide I band is more sensitive to the change of protein secondary structure than amide II (He et al., 2005). Figure 8 shows the FT-IR spectra of free and TPL-bound form of HSA with its difference absorbance spectrum. The spectrum in Fig. 8a was obtained by subtracting the absorbance of phosphate buffer from the spectrum of protein solution. The difference spectrum shown in Fig. 8b was obtained by subtracting the spectrum of TPL+ buffer from that of the TPL-bound HSA. The evident peak shift of amide I band from 1642.60 to $1654.01 \mathrm{~cm}^{-1}$ and the appearance of new peaks in Fig. $8 \mathrm{~b}$ indicate that the secondary structure of HSA is changed when TPL is added.

\section{Circular dichroism studies}

In this work, the molar ratios of 1:10, 1:11, 1:12 and 1:14 for HSA/TPL were used to prepare sample for $\mathrm{CD}$ measurements. Each sample contained fixed concentration of protein $(6 \mu \mathrm{M})$ with varied drug concentration. The CD spectra of HSA in the absence (line a) and presence (lines b to e) of TPL are shown in Fig. 9. The CD spectra of HSA exhibited two negative bands in the UV region at 208 and $220 \mathrm{~nm}$, characteristic of an $\alpha$-helical structure of protein (Hu et al., 2005). The CD results were expressed in terms of mean residual ellipticity (MRE) in $\mathrm{deg} \cdot \mathrm{cm}^{2} \cdot \mathrm{dmol}^{-1}$ according to the following equation:

$$
[\theta]=\frac{\text { observed } \mathrm{CD}(\mathrm{mdeg})}{C \mathrm{p} n l \times 10}
$$

Where $[\theta]$ is mean residual ellipticity, $C p$ is the molar concentration of the protein, $n$ the number of amino-acid residues and $l$ is the path length. The instrument was installed with software based on Yang equation (Chen et al., 1971) to calculate the secondary structure content in the protein. The CD spectrum of native HSA alone showed very neat

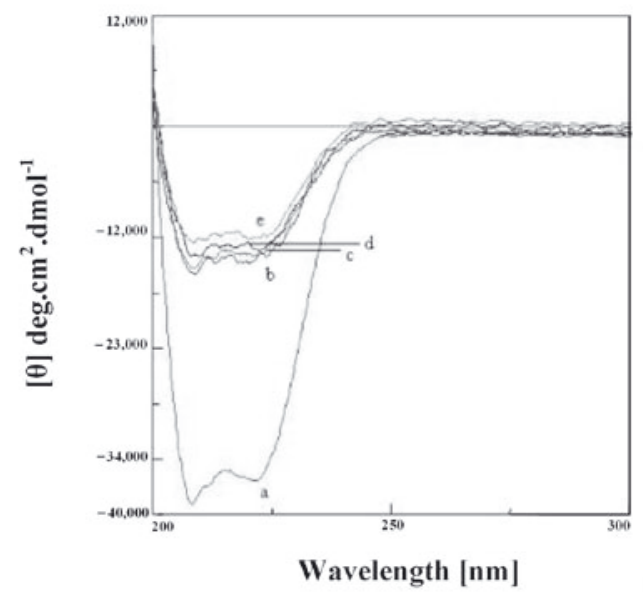

Figure 9. Secondary structure estimation by circular dichroism.

Far UV-CD spectra of HSA of native, (a); native $+30 \mu \mathrm{M}$ TPL, (b); native $+33 \mu \mathrm{M}$ TPL, (c); native + $36 \mu \mathrm{M}$ TPL, (d); native + $42 \mu \mathrm{M}$ TPL, (e); respectively.

Table 5. The binding constants $K^{\prime}\left(\mathrm{M}^{-1}\right)$ between TPL and $\mathrm{HSA}$ at $25^{\circ} \mathrm{C}$ in the presence of divalent ions

\begin{tabular}{lccc}
\hline Ions & $K^{\prime}\left(\times 10^{3}\right)$ & $\mathrm{R}^{2}$ & $K^{\prime} / K$ \\
\hline $\mathrm{Ca}$ & 4.50 & 0.9755 & 1.78 \\
$\mathrm{Mn}$ & 13.00 & 0.9980 & 5.15 \\
$\mathrm{Zn}$ & 2.60 & 0.9969 & 1.03 \\
$\mathrm{Cu}$ & 83.50 & 0.9825 & 33.13 \\
$\mathrm{Ni}$ & 31.50 & 0.9893 & 12.50 \\
$\mathrm{Fe}$ & 9.28 & 0.9928 & 1.76 \\
\hline
\end{tabular}

peaks at 208 and $222 \mathrm{~nm}$, which are negative in Fig. 9. Addition of TPL resulted in drastic reduction in ellipticity (curve b), which further reduces on addition of the TPL (Fig. 9; curve c, d and e). The change in ellipticity is accompanied by a decrease in both $\alpha$-helix and $\beta$-sheet structures (Table 4) illustrating the change in the secondary structure of HSA. It is important to note that saturable binding of some anesthetics to HSA induces alterations in the structure and function of this protein. However, competitive binding displayed by different ligands may result from allosteric effects, whereby binding of ligand $\mathrm{A}$ at a certain site causes a conformational change in the protein so that binding of ligand $\mathrm{B}$ at a different site is altered (Miles et al., 1962).

\section{Energy transfer between TPL and protein}

The spectral studies suggested that HSA forms a complex with TPL. HSA has a single tryptophan residue (Trp-214). The distance $r$ between Trp-214 in HSA and the bound TPL could be determined using fluorescence resonance energy transfer (FRET) (Jiaquin et al., 2003). Generally, FRET occurs whenever the emission spectrum of a fluorophore 


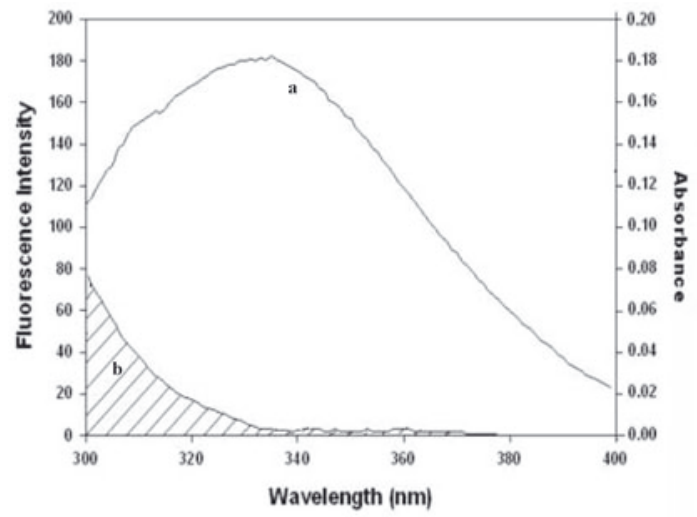

Figure 10. Förster resonance energy transfer (FRET). Overlap of fluorescence spectrum of HSA (a) and the absorbance spectrum of TPL (b) $[c(\mathrm{HSA}) / c($ TPL $)=1: 1]$.

(donor) overlaps the absorbance spectrum of another molecule (acceptor). The overlap of the UV absorbance spectrum of TPL with the fluorescence emission spectra of HSA is shown in Fig. 10. The distance between the donor and acceptor and extent of spectral overlaps determines the extent of energy transfer. The distance between the donor and acceptor can be calculated according to Förster's theory (Förster \& Sinanoglu, 1996). The efficiency of energy transfer, $E$, is calculated using the equation:

$E=1-\frac{F}{F_{0}}=\frac{R_{0}^{6}}{R_{0}^{6}+r^{6}}$

where $F$ and $F_{0}$ are the fluorescence intensities of HSA in the presence and absence of TPL, $r$ is the distance between acceptor and donor, and $R_{0}$ is the critical distance when the transfer efficiency is $50 \%$.

$R_{0}^{6}=8.8 \times 10^{-25}\left(k^{2} \eta^{-4} \Phi\right)$

where $k^{2}$ is the spatial orientation factor of the dipole, $\eta$ the refractive index of the medium, $\Phi$ the fluorescence quantum yield of the donor and $J$ is the overlap integral of the fluorescence emission spectrum of the donor and the absorbance spectrum of the acceptor. $J$ is given by equation:

$\mathrm{J}=\frac{\sum F(\lambda) \varepsilon(\lambda) \lambda^{4} \Delta \lambda}{\sum F(\lambda) \Delta \lambda}$

where $F(\lambda)$ is the fluorescence intensity of the fluorescent donor at wavelength, $\lambda$, and $\varepsilon(\lambda)$ is the molar absorption coefficient of the acceptor at wavelength, $\lambda$. In the present case, $k^{2}=2 / 3, N=1.336$ and $\Phi=0.118$ for HSA (Epps et al., 1999). From Eqns. (9) to (11), we were able to calculate that $J=2.3 \times 10^{-15}$ $\mathrm{cm}^{3} \mathrm{~L} \mathrm{~mol}^{-1}, R_{0}=1.92 \mathrm{~nm}, E=0.24$ and $r=2.32 \mathrm{~nm}$ for HSA. The donor-to-acceptor distance, $r<8 \mathrm{~nm}$ (Valeur \& Brochon, 1999), indicated that the energy transfer from HSA to TPL occurs with high possibility. Larger HSA-TPL distance $(r)$ to that of critical distance $\left(R_{0}\right)$, also reveals the presence of static type quenching mechanism (Valeur \& Brochon, 1999; He et al., 2005).

The effect of ions on the binding constant of TPLprotein

In plasma, there are some metal ions which can affect the reactions of drugs with serum albumins. The effects of common ions, viz., $\mathrm{Cu}^{2+}, \mathrm{Fe}^{3+}$, $\mathrm{Ni}^{2+}, \mathrm{Zn}^{2+}, \mathrm{Mn}^{2+}$ and $\mathrm{Ca}^{2+}$ on the binding constants of the TPL-HSA system were investigated at $298 \mathrm{~K}$ by recording the fluorescence intensity in the range of 300-400 nm upon excitation at $280 \mathrm{~nm}$. As evident from Table 5, the presence of metal ions increased the basic binding constants $(K)$ to $\left(K^{\prime}\right)$, showing an increased persistence of TPL in the blood and so its effects, which may lead to the need for dose reduction of TPL to achieve the desired therapeutic effect (Li et al., 2005; Pang et al., 2005). $K^{\prime} / K$ signifies the fold increase in the binding constant.

\section{CONCLUSION}

TPL is a common intravenously administered barbiturate anesthetic and its interaction with serum albumin is of prime significance. The interaction was investigated by UV-visible, fluorescence, FT-IR and CD spectroscopic techniques. The UV-visible spectroscopy reveals a red-shift which is indicative of TPL binding with HSA. The fluorescence spectroscopy revealed a complex formation at 1:1 concentration of TPL and HSA at physiological $\mathrm{pH}$. The interaction was linearly dependent on HSA concentration. The TPL binding was also found to be conformation-dependent and the highest association constant was observed for the F-isomer of HSA. The TPL-binding pockets were found to be located on domain-II of the protein. The static type of quenching is indicative of a complex formation between the protein and the drug molecule. Drug interactions will in most cases significantly affect the apparent distribution volume of the drugs and also affect the elimination rate and determine the therapeutic affectivity of drugs. At the plasma concentration of HSA the fraction of free drug was found to be $71 \%$ more for $\mathrm{N}$ isomer than $\mathrm{F}$ isomer. The binding is mediated mainly by hydrogen bonding and hydrophobic interaction. The perturbation of protein secondary structure on TPL binding is suggestive of anesthetic induced protein dysfunction. 


\section{Acknowledgements}

We are thankful to the central instrumentation facility of IBU. This work was supported by the CSIR sanction no. 37(1209)04 EMR II. The authors S.N.K. and B.I. acknowledge the fellowship from CSIR, India.

\section{REFERENCES}

Ahmad B, Parveen S, Khan RH (2006) Effect of albumin conformation on the binding of ciprofloxacin to human serum albumin: a novel approach directly assigning binding site. Biomacromolecules : 1350-1356.

Aki H, Yamamoto M (1989) Thermodynamics of the binding of phenothiazines to human plasma, human serum albumin and alpha 1-acid glycoprotein: a calorimetric study. J Pharm Pharmacol 41: 674-679.

Borga O, Borga B (1997) Serum protein binding of nonsteroidal anti-inflammatory drugs: a comparative study. $J$ Pharmcokinet Biopharm 25: 63-77.

Chamouard JM, Barre J, Urien S, Houin G, Tillement JP (1985) Diclofenac binding to albumin and lipoproteins in human serum. Biochem Pharmacol 34: 1695-1700.

Chen YH, Yang JT (1971) A new approach to the calculation of secondary structures of globular proteins by optical rotatory dispersion and circular dichroism. Biochem Biophys Res Commun 44: 1285-1291.

Chmelik J, Kalous V (1982) Polarographic investigation of conformational changes of human serum albumin. Bioelectrochem Bioenerg 9: 7-13.

Cui F-L, Fan J, Li J-P, Hu Z (2004) Interactions between 1benzoyl-4- $p$-chlorophenyl thiosemicarbazide and serum albumin: investigation by fluorescence spectroscopy. Bioorg Med Chem 12: 151-157.

Dugaiczyk A, Law SW, Dennison OE (1982) Nucleotide sequence and the encoded amino acids of human serum albumin mRNA. Proc Natl Acad Sci USA 79: 71-75.

Epps DE, Raub TJ, Caiolfa V, Chiari A, Zamai M (1999) Determination of the affinity of drugs toward serum albumin by measurement of the quenching of the intrinsic tryptophan fluorescence of the protein. J Pharm Pharmacol 51: 41-48.

Förster T, Sinanoglu O, eds (1996) Modern Quantum Chemistry, p. 93. Academic Press, New York.

Feng X-Z, Lin, Z, Yang L-J, Wang C, Bai C-L (1998) Investigation of the interaction between acridine orange and bovine serum albumin. Talanta 47: 1223-1229.

Gao H, Lei L, Liu J, Qin K, Chen X, Hu Z (2004) The study on the interaction between human serum albumin and a new reagent with antitumour activity by spectrophotometric methods. J Photochem Photobiol Part A 167: 213-221.

Gelamo EL, Silva CHTP, Imasato H, Tabak M (2002) Interaction of bovine (BSA) and human (HSA) serum albumins with ionic surfactants: spectroscopy and modeling. Biochim Biophys Acta 1594: 84-99.

Giraud O, Dehoux M, Rolland C, Mantz J, Malas V, Toueg ML, Desmonts JM, Aubier M (1998) Differential effects of halothane and thiopental on the lung inflammatory response after LPS-induced lung injury in the rat. Anesthesiology 89: 34-38.

He W, Li Y, Xue C, Hu Z, Chen X, Sheng F (2005) Effect of Chinese medicine alpinetin on the structure of human serum albumin. Bioorg Med Chem 13: 1837-1845.
Hu YJ, Liu Y, Wang JB, Xiao XH, Qu SS (2004) Study of the interaction between monoammonium glycyrrhizinate and bovine serum albumin. J Pharm Biomed Anal 36: 915-919.

Hu YJ, Liu Y, Shen XS, Fang XY, Qu SS (2005) Studies on the interaction between 1-hexylcarbamoyl-5-fluorouracil and bovine serum albumin. J Mol Struct 738: 143-147.

Jiaquin L, Jianniao T, Zhang J, Hu Z, Xingguo C (2003) Interaction of magnolol with bovine serum albumin: a fluorescence-quenching study. Anal Bioanal Chem 376: 864-867.

Khan MY (1986) Direct evidence for involvement of domain III in the N-F transition of bovine serum albumin. Biochem J 236: 307-310.

Khan SN, Islam B, Khan AU (2007) Probing midazolam interaction with human serum albumin and its effect on structural state of protein. Int J Integ Biol 2: 102-112.

Kragh-Hansen U (1981) Molecular aspects of ligand binding to serum albumin. Pharmacol Rev 33: 17-53.

Krier C, Wiedemann K, Polarz H (1984) Hazards of high dose barbiturate therapy in head-injury patients. Acta Anaesthesiol Belg 35: 361-369.

Li Y, He W, Liu J, Sheng F, Hu Z, Chen X (2005) Binding of the bioactive component jatrorrhizine to human serum albumin. Biochim Biophys Acta 1722: 15-21.

Lloyd JBF (1971) Synchronized excitation of fluorescence. ernission spectra. Nat Phys Sci 231: 64-65.

Martin BK (1965) Potential effect of the plasma proteins on drug distribution. Nature 207: 274-276.

Miles JL, Morey E, Crain F, Gross S, San Julian J, Canady WJ (1962) Inhibition of $\alpha$-chymotrypsin by diethyl ether and certain alcohols: a new type of competitive inhibition. J Biol Chem 237: 1319-1322.

Miller JN (1979) Recent advances in molecular luminescence analysis. Proc Anal Div Chem Soc 16: 203-208.

Neault JF, Tajmir-Riahi HA (1998) Interaction of cisplatin with human serum albumin: Drug binding mode and protein secondary structure. Biochem Biophys Acta 1384: 153-159.

Pang YH, Yang LL, Shuang SM, Dong C, Thompson M (2005) Interaction of human serum albumin with bendroflumethiazide studied by fluorescence spectroscopy. J Photochem Photobiol Part B 80: 139-144.

Peters T Jr (1996) All about albumin: biochemistry, genetics and medical application. Academic Press, Inc, NY.

Rahman MH, Maruyama T, Okada T, Yamasaki K, Otagiri M (1993) Study of interaction of carprofen and its enantiomers with human serum albumin-I. Biochem Pharmacol 46: 1721-1731.

Ross PD, Subramanian S (1981) Thermodynamics of protein association reactions. Forces contributing to stability. Biochemistry 20: 3096-3102

Ryan CW, Vogelzang NJ, Vokes EE, Kindler HL, Undevia SD, Humerickhouse R, Andre AK, Wang Q, Carr RA, Ratain MJ (2004) Dose-ranging study of the safety and pharmacokinetics of atrasentan in patients with refractory malignancies. Clin Cancer Res 10: 4406-4411.

Schalen W, Messeter K, Nordstrom CH (1992) Complications and side effects during thiopentone therapy in patients with severe head injuries. Acta Anaesthesiol Scand 36: 369-377.

Seedher N, Singh B, Singh P (1999) Mode of interaction of metronidazole with bovine serum albumin. Indian J Pharm Sci 61: 143-148.

Sereikaite J, Bumelis VA (2006) Congo red interaction with $\alpha$-proteins. Acta Biochim Polon 53: 87-92.

Skarlosh (1974) Effect of thiopental sodium on the biligenic function of the liver. Farmacol Toksikol 37: 701-702. 
Surewicz WK, Mantsch HH, Chapman D (1993) Determination of protein secondary structure by Fourier-transform infrared spectroscopy: a critical assessment. Biochemistry 32: 389-394.

Tian JN, Liu JQ, Zhang JY, Hu ZD, Chen XG (2003) Fluorescence studies on the interactions of barbaloin with bovine serum albumin. Chem Pharm Bull 51: 579-582.

Valeur B, Brochon JC (1999) New Trends in Fluorescence Spectroscopy. 6th edn, p. 25. Springer Press, Berlin.
Ware WR (1962) Oxygen quenching of fluorescence in solution, an experimental study of the diffusion process. J Phys Chem 66, 455-458.

Wilting J, Vander Glesen WF, Janssen LH, Weideman MM, Otagiri M, Perrin JH (1980) The dependence of the binding of warfarin to human serum albumin on the hydrogen, calcium and chloride ion concentrations as studied by circular dichroism, fluorescence, and equilibrium dialysis. J Biol Chem 255: 3032-3037. 